Proc. of the X Int. Conf. - Ion Implantation and other Applications of Ions and Electrons, Kazimierz Dolny 2014

\title{
Carbon Doped Austenitic Stainless Steel Coatings Obtained by Reactive Magnetron Sputtering
}

\author{
S. Fryska*, P. GizA, R. JedrzejeWski And J. BARANOWskA \\ Institute of Materials Science, West Pomeranian University of Technology, \\ al. Piastów 19, 70-310 Szczecin, Poland
}

\begin{abstract}
The paper presents the results of investigations of carbon doped austenitic stainless steel coatings (carbon Sphase) obtained by the reactive magnetron sputtering in the reactive atmosphere composed of argon and methane as a carbon source. Stainless steel targets were sputtered under different conditions. During the experiments the argon to methane proportion varied within a range $11 / 2-7 / 6$. The other parameters such as temperature, pressure, sputtering power, etc. were kept constant. The phase composition was determined using the X-ray diffraction. Electron probe microanalysis (energy dispersive spectroscopy and wavelength dispersive spectroscopy) and glow discharge optical emission spectrometry techniques were used to study element composition of the coatings. Microstructure was investigated by scanning electron microscopy. It was found that varying the methane volume in the reactive atmosphere, it is possible to control the lattice parameter of the carbon S-phase.
\end{abstract}

DOI: 10.12693/APhysPolA.128.879

PACS: 68.60.-p, 68.60.Bs, 68.55.J-, 81.15.-z

\section{Introduction}

Austenitic stainless steel is an important structural material owing to its very good corrosion resistance and good mechanical properties. However, poor tribological properties and hardness seriously limit the areas of its applications. Surface engineering is one of the main ways to overcome these limitations. One of the methods to improve mechanical characteristics of austenitic stainless steel without impairing its corrosion resistance is production of the so-called S-phase coatings. S-phase is a phase with very high hardness and good corrosion resistance which demonstrates a large potential for many practical applications. It is considered to be a supersaturated solution of carbon or nitrogen in austenitic stainless steel [1]. This phase is mostly obtained by the so-called low-temperature processes, which refers to the plasma or gas nitriding or carburising at a temperature below $500{ }^{\circ} \mathrm{C}$. The S-phase is metastable and extremely sensitive to overheating which leads to precipitation of either nitrides or carbides and negatively affects corrosion resistance of steel. Applying plasma or gas thermochemical treatment, the S-phase can be obtained at the temperatures between 350 and $500{ }^{\circ} \mathrm{C}$. Temperature rise increases the risk of carbon or nitrides precipitations while temperature decrease reduces seriously the time of layer growth [2].

The S-phase can be also produced in an effective way by reactive magnetron sputter deposition even at a very low temperature (below $200^{\circ} \mathrm{C}$ ) $[3-5]$. This process as well the layer composition allow to be better controlled. The carbon or nitrogen composition is uniform within the

${ }^{*}$ corresponding author; e-mail: Sebastian.Fryska@zut.edu.pl coating in contrast to the gradient layers produced during thermochemical surface treatment $[2,4]$. The deposition of nitrogen doped S-phase coatings by magnetron sputtering was very little investigated and even less is known about the deposition of carbon doped S-phase coatings [5-7].

One of the characteristics of S-phase is that it demonstrates a wide range of carbon or nitrogen solubility. It was reported that nitrogen content in S-phase obtained by the surface thermochemical treatment can vary in the range $20-30$ at.\% while for carbon it can reach the values up to 15 at.\% [1].

The change in nitrogen or carbon content in S-phase has an influence on its lattice parameter, which in nitrogen doped S-phase can be increased even by $10 \%$ in comparison with the austenite lattice [8]. It is a very interesting feature which could allow the stress level in coatings to be better controlled. The main objective of this paper was to investigate the possibility of controlling lattice parameter of carbon doped S-phase coatings by controlling carbon carrier volume in the reactive atmosphere during magnetron sputtering deposition.

\section{Experimental}

The coatings were obtained by reactive magnetron sputtering in the atmosphere composed of argon and methane as a carbon source. Three austenitic stainless steel targets (X2CrNi18-9) were sputtered under different conditions. The same steel was used as a deposition substrate. The samples were grounded, polished by the use of sandpaper and diamond suspension. Final polishing was carried out in aluminium oxide to achieve roughness $R_{\mathrm{a}}$ below $0.05 \mu \mathrm{m}$. Afterwards, vibropolishing was performed to remove ferrite created during hand mechanical polishing. Finally, substrates were ultrasonically cleaned for $15 \mathrm{~min}$ in acetone and dried in hot air. 
The pressure was pumped down to $10^{-6} \mathrm{~Pa}$ and argon was introduced once the temperature of $200{ }^{\circ} \mathrm{C}$ in the chamber was reached. Before opening targets shutters the stainless steel targets were sputter-cleaned for $15 \mathrm{~min}$ at $-170 \mathrm{~V}$ and 2.7 Pa. After initial cleaning methane gas was introduced into the chamber and total pressure was adjusted to the $0.8 \mathrm{~Pa}$. During the experiments argon to methane proportion varied within a range $11 / 2-7 / 6$. Other parameters as temperature, pressure, sputtering power, etc. were kept constant. The process parameters are summarized in Table I. The samples order is presented in Table II.

TABLE I

Coatings deposition conditions used in experiments.

\begin{tabular}{c|c}
\hline \hline Substrate & $\mathrm{X} 2 \mathrm{CrNi} 18-9$ \\
Substrate temperature & $200{ }^{\circ} \mathrm{C}$ \\
Ar $/ \mathrm{CH}_{4}$ ratio & $0.15,0.23,0.31,0.38,0.46$ \\
Target & $\mathrm{X} 2 \mathrm{CrNi} 18-9$ \\
Total gas flow rate & $13 \mathrm{sccm}$ \\
Sputtering pressure & $0.8 \mathrm{~Pa}$ \\
Power & $200 \mathrm{~W}$ \\
Substrate bias & $-50 \mathrm{~V}$ \\
Deposition time & $2 \mathrm{~h}$
\end{tabular}

TABLE II

Ar to methane volume ratio of the studied samples.

\begin{tabular}{c|c|c|c|c|c}
\hline \hline $\mathrm{Ar} / \mathrm{CH}_{4}$ & $11 / 2$ & $10 / 3$ & $9 / 4$ & $8 / 5$ & $7 / 6$ \\
\hline Sample No. & 1 & 2 & 3 & 4 & 5
\end{tabular}

The phase composition of the coatings was determined by X-ray diffraction using the X'PERT PANALYTICAL diffractometer with $\mathrm{Cu} K_{\alpha}$ radiation. The BraggBrentano geometry was applied within the angle range $2 \Theta=30 \div 120^{\circ}$. Grazing angle incidence scan with a fixed incidence angle of $3^{\circ}$ was also performed. Electron probe microanalysis (energy dispersive spectroscopy (EDS), wavelength dispersive spectroscopy (WDS); Thermo Scientific, Hitachi SU-70) and glow discharge optical emission spectrometry (GDOES; GDPROFILER 2, HORIBA Jobin Yvon) techniques were used to study element composition of the coatings. Surface morphology was investigated by scanning electron microscopy (Hitachi SU-70) and atomic force microscopy (AFM; MultiMode IV, Veeco) was used to examine surface topography. Thickness of the coatings was measured by a profilometer (DEKTAK 6M, Veeco). During the deposition process a part of the sample was shadowed and the thickness differences between the surfaces of uncovered substrate and the coating were measured.

\section{Results and discussion}

It was found that the volume of methane in the atmosphere affects both the concentration of carbon in the coatings (Fig. 1) and the speed of their deposition
(Fig. 2). A linear increase in the carbon content in the coating with an increase of methane volume in the reactive atmosphere was obtained which is consistent with other research studies [5]. For the analyzed range of methane volume, the coatings containing carbon between 2.3 and 8.4 at.\% were obtained. These values are much higher than those mentioned in the literature [1] for the layers produced by surface thermochemical treatment. However, they are consistent with the data presented by other researchers for the layers deposited by magnetron sputtering method $[5,6]$. At the same time an increase of methane rate caused the slowdown in the deposition process which is also consistent with the paper presented by Barbee et al. [6], where the decrease of film deposition rate with the increase of carbon content in the coating was reported.

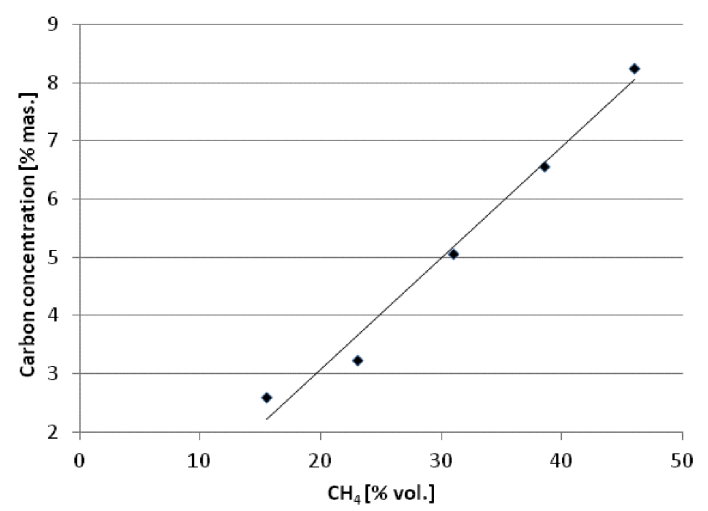

Fig. 1. Carbon concentration in the coatings versus methane content in reactive atmosphere.



Fig. 2. Relation between coating thickness and methane content in reactive atmosphere.

The resulting coatings were characterized by a finegrained structure with a grain size in the nanometer and submicroscopic range (Fig. 3). Increasing grain refinement was observed as long as the carbon content in the coatings was increasing which is also consistent with the observations of other researchers $[5,6,9]$. More thorough observation of the surface by SEM demonstrated that the microstructure of the coatings is much finer and those submicroscopic grains are composed of much smaller nanosize grains. An example of such structure is shown in Fig. 3d. However, such a strong amorphization of the microstructure as mentioned in the above cited papers was not observed. 

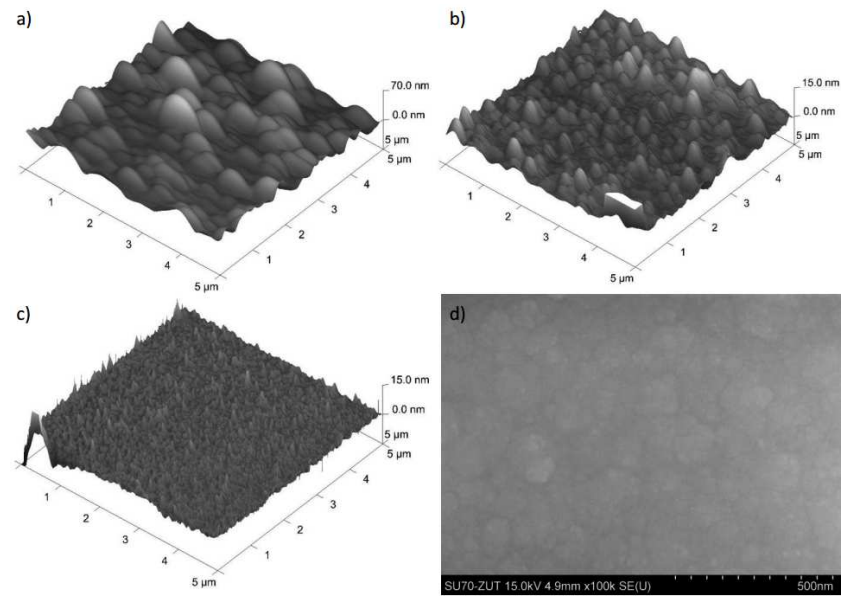

Fig. 3. Topography of coatings: (a) 1 , (b) 4 , (c) 5, AFM, (d) microstructure of the coating 5, SEM.

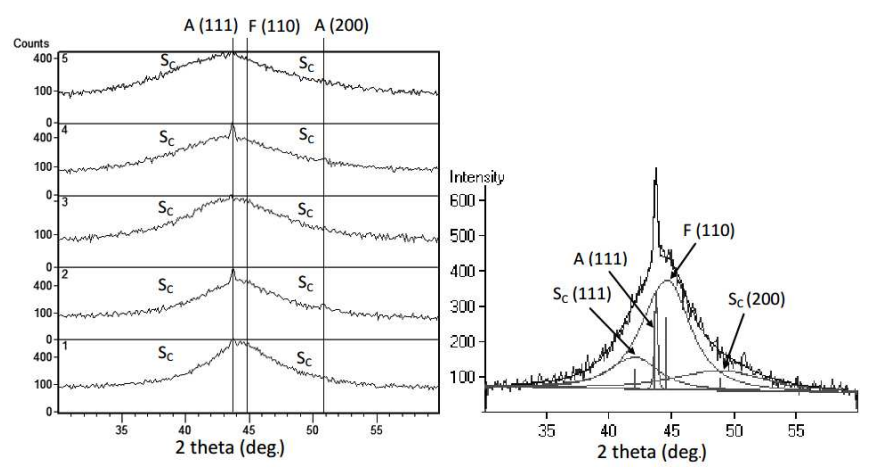

Fig. 4. (a) Diffraction patterns of the coatings obtained in experiments; (b) an example of diffraction pattern deconvolution for coating 2, GXRD.

No diffraction peaks were obtained when the X-ray diffraction in the Bragg-Brentano geometry was used. It was probably due to strong refinements of the grains. However, the research conducted by means of grazing angle diffraction demonstrated however, the presence of very broad reflections with low intensity (Fig. 4a). The deconvolution of these diffraction patterns revealed a series of reflections as shown in Fig. 4b. Two of them were assigned to the carbon S-phase as originating from diffraction on (111) and (200) planes. Moreover, in the samples 1-4 the additional broad peak was detected. It was placed in the angle range of $44.4-44.6^{\circ}$. This peak can be attributed to ferrite (110) planes. The presence of bcc structure was frequently observed by other researchers $[5,6,9]$ in the coatings deposited by magnetron sputtering of stainless steel below $375^{\circ} \mathrm{C}$ which corresponds to the conditions of this experiment. The formation of ferrite is explained by the rapid cooling occurring under the deposition conditions which favours the formation of ferrite in the place of austenite [10]. It was also reported that increase of carbon or nitrogen content in reactive atmosphere facilitate the formation of fcc-like structure, and ferrite-like structures disappear, which was observed in the present research of the coatings with the highest carbon content as well. The additional sharp peak detected in the diffraction patterns is in the position of austenite and originated from the austenitic substrate. No peaks of carbides were detected from the diffraction studies.

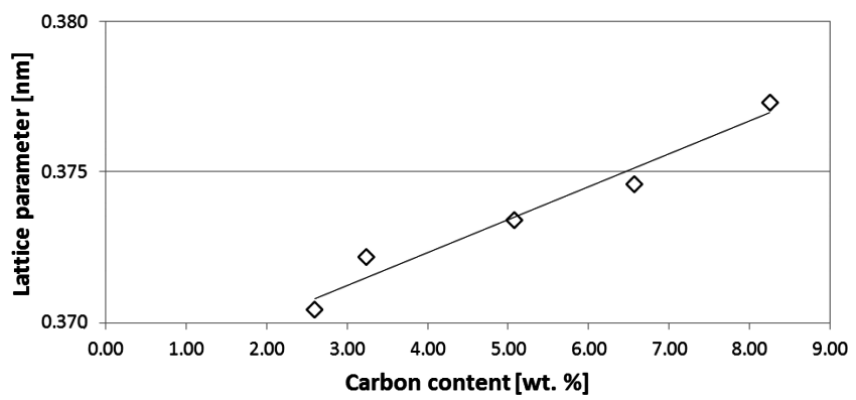

Fig. 5. Relation between carbon S-phase lattice parameter and carbon concentration in the coatings.

The position of reflections from the carbon S-phase depended on the content of carbon in this phase. A linear dependence of the average lattice parameter (measured for the reflections originating from (111) and (200) planes) on the carbon content was obtained (Fig. 5). For the carbon concentration in the deposited coatings, the broadening of lattice parameters of carbon S-phase was between 2.8 and $4.7 \%$ in comparison to the austenite lattice parameter. These values are much greater than those obtained for the carbon S-phase produced at low temperature gas carburizing. Christiansen et al. [1] registered an increase of lattice parameters from 1.7 to $2.5 \%$, but this is due to much lower carbon concentration obtained in their paper.

\section{Conclusions}

1. During the reactive sputter deposition of austenitic stainless steel in the atmosphere containing methane, it is possible to obtain the carbon doped S-phase with the carbon content up to $8 \mathrm{wt} \%$, which represents much higher values than those reported for low temperature carburization of austenitic stainless steel. No presence of carbides was revealed by the X-ray diffraction method.

2. The carbon content in the S-phase coatings depends in a linear way on the volume of carbon carrier (methane) in the reactive atmosphere and can be easily controlled by gas flow rate.

3. The increasing content of carbon causes the expansion of the S-phase cell and the linear dependence of the lattice parameter on the carbon concentration in S-phase was observed. The range of carbon concentrations between 2.6 and $8.25 \mathrm{wt} \%$, produced the linear cell expansion between 2.86 and $4.7 \%$. 


\section{Acknowledgments}

The project was funded by the National Centre for Science granted on the basis of decision No. UMO2011/03/B/ST8/06130.

\section{References}

[1] Th.L. Christiansen, Th.S. Hummelshoj, M.A.J. Somers, Low temperature thermochemical treatment of stainless steel; bridging from science to technology, Technical University of Denmark, Lyngby.

[2] J. Baranowska, Def. Diff. Forum 297-301, 297 (2010).

[3] K.L. Dahm, P.A. Dearlney, Surf. Eng. 12, 61 (1996).
[4] J. Baranowska, S. Fryska, T. Suszko, Vacuum 50, 160 (2013).

[5] A. Billard, M. Foos, C. Frantz, M. Gantois, Surf. Coat. Technol. 43/44, 521 (1990).

[6] T.W. Barbee, B.E. Jacobson, D.L. Keith, Thin Solid Films 63, 143 (1979).

[7] S. Malavasi, A. Oueldennaoua, M. Foos, C. Frantz, Mem. Etud. Sci. Rev. Met. 11, 553 (1986).

[8] S. Maendl, B. Rauschenbach, Def. Diff. Forum 188190, 125 (2001).

[9] S. Malavasi, A. Oueldennaoua, M. Foos, C. Frantz, J. Vac. Sci. Technol. A 5, 1888 (1987).

[10] M.J. Godbole, A.J. Pedraza, J.W. Park, G. Geesey, Scr. Metall. Mater. 28, 1201 (1993). 